\title{
Influence of plant growth regulators on the shoot culture of Phyllanthus glaucus and accumulation of indolizidine alkaloids with evaluation of antimicrobial activity
}

\author{
Barbara Sparzak-Stefanowska ${ }^{1} \cdot$ Mirosława Krauze-Baranowska ${ }^{1} \cdot$ Rafał Hałasa $^{2}$
}

Received: 20 April 2018 / Revised: 28 November 2018 / Accepted: 8 December 2018 / Published online: 18 December 2018

(C) The Author(s) 2018

\begin{abstract}
In the presented studies, plant growth regulators (PGRs) were evaluated for their influence on the shoot development and the content of biologically active indolizidine alkaloids, securinine, and allosecurinine in Phyllanthus glaucus (Euphorbiaceae) in vitro shoot cultures. The experiments included five cytokinins [kinetin, 6-benzylaminopurine (BAP), 2-isopentenyladenine, and thidiazuron] and two auxins [indole-3-acetic acid and indole-3-butyric acid (IBA)] used in a different concentrations. The results were tested for statistical differences. The highest number of shoot per explant (11.5) was achieved on Murashige and Skoog's (MS) medium supplemented with IBA $0.5 \mathrm{mg} / \mathrm{L}$ and BAP $1.0 \mathrm{mg} / \mathrm{L}$, and the optimal rooting response (87.50\%) was obtained on MS medium-containing IBA $1.0 \mathrm{mg} / \mathrm{L}$. The rooted plantlets were transferred into the soil and the survival rate was $70.0 \%$. The differences in accumulation of particular alkaloids were revealed depending on PGRs present in harvesting medium. The highest total concentration of alkaloids was determined in the shoot culture grown in the presence of BAP $0.5 \mathrm{mg} / \mathrm{L}[5.82 \mathrm{mg} / \mathrm{g}$ dry weight (DW)]. In routine propagation, MS medium supplemented with IBA $0.5 \mathrm{mg} / \mathrm{L}$ and BAP $0.5 \mathrm{mg} / \mathrm{L}$ was used as a compromise between the relatively high proliferation rate $(\sim 8$ shoots/explant $)$ and the total content of alkaloids $(4.73 \mathrm{mg} / \mathrm{g} \mathrm{DW})$. The antimicrobial activity of the biomass and isolated securinine was evaluated towards 12 strains of bacteria and one fungal strain. The differences in bacterial susceptibility against $P$. glaucus extract and securinine were showed. The MBC values range from 0.01 to $5 \mathrm{mg} / \mathrm{mL}$ and from 0.063 to $0.250 \mathrm{mg} / \mathrm{mL}$, respectively, for extract and securinine.
\end{abstract}

Keywords Securinine $\cdot$ Allosecurinine $\cdot$ Securinega-type alkaloids $\cdot$ Plant growth regulators $\cdot$ Phyllanthus glaucus . Antimicrobial activity

\section{Introduction}

The occurrence of alkaloids in the genus Phyllanthus is relatively rare. Until now, it has been confirmed only to a few species, e.g., P. niruroides (niruroidine), P. amarus (phyllan-

Communicated by J van Staden.

Mirosława Krauze-Baranowska

krauze@gumed.edu.pl

Barbara Sparzak-Stefanowska

bsparzak@gumed.edu.pl

Rafał Hałasa

halasar@gumed.edu.pl

1 Department of Pharmacognosy with Medicinal Plants Garden, Medical University of Gdańsk, 80-210 Gdańsk, Poland

2 Department of Pharmaceutical Microbiology, Medical University of Gdańsk, 80-210 Gdańsk, Poland thine, securinine, norsecurinine, isobubbialine, and epibubbialine), $P$. discoideus (14,15-dihydroallosecurinine-15 $\beta$-ol, securinine, and viroallosecurinine), $P$. simplex (phyllanthine and simplexine) or P. niruri (Babady et al. 1996; Calixto et al. 1998; Houghton et al. 1996; Mensah et al. 1988; Negi and Fakhir 1988; Zhou et al. 2012). Recent research revealed the presence of alkaloid fraction in the shoot culture of Phyllanthus glaucus Wall. ex Mü 1l. Arg. harvested in vitro that contained securinega-type alkaloids - securinine and allosecurinine, as dominating compounds (Sparzak et al. 2015).

Securinega-type alkaloids belong to the group of indolizidine alkaloids. These are tetracyclic compounds 
which fused a 6-azobicyclooctane structure with an $\alpha, \beta$-unsaturated- $\gamma$-lactone moiety and a piperidine ring (Beutler and Brubaker 1987).

These rare compounds are present mainly in Securinega species and possess unique biological activity (Zhang et al. 2011). Securinine, the most well-known securinegatype alkaloid, is stereospecific $\mathrm{GABA}_{\mathrm{A}}$ receptor antagonist (Beutler et al. 1985; Gupta et al. 2011).

It acts as a significant in vivo CNS stimulant, shows neuroprotective properties, and enhances learning and memory processes. Some data indicate that this compound may improve neurodegeneration and cognitive deficits, which are induced by $\beta$-amyloid proteins and also may be useful in the treatment of Alzheimer's disease. Securinine also decreases glial inflammatory responses induced by $\beta$-amyloid proteins and clearly reduces acetylcholinesterase activity (Lin and Jun-Tian 2004).

Moreover, securinega-type alkaloids showed antiviral, antibacterial, antimalarial, and antitumor activity (Dong et al. 1999; Mensah et al. 1988; Zhang et al. 2011). Recently, the cytotoxic activity of securinine was investigated against several cancer cell lines-breast (MCF7), colon (HCT-116), and leukemia (HL-60) (Dong et al. 1999; Li et al. 2014; Rana et al. 2010; Xia et al. 2011). The study showed that securinine possesses significantly higher activity to the HeLa cells than allosecurinine with $\mathrm{IC}_{50}$ values of $7.02 \pm 0.52 \mu \mathrm{g} / \mathrm{mL}(32.3 \mu \mathrm{M})$ and $52.88 \pm 4.62 \mu \mathrm{g} / \mathrm{mL}(243.4 \mu \mathrm{M})$, respectively (Stefanowicz-Hajduk et al. 2016).

Scientific data regarding securinega-type alkaloids in Phyllanthus species are limited and mostly relate to isolation methods (Babady et al. 1996; Houghton et al. 1996; Negi and Fakhir 1988). In the literature, there are described research concerning the influence of plant growth regulators on the accumulation of securinega-type alkaloids in in vitro conditions; however, none of these concern Phyllanthus species (Raj et al. 2015; Yuan et al. 2007). In addition, the method for micropropagation of Phyllanthus species as a source of securinega-type alkaloids has not been provided yet. According to these data, the aim of the study was to evaluate the influence of plant growth regulators (40 modifications in total) on the development of shoot culture of P. glaucus Wall. ex Mü ll. Arg., and accumulation of indolizidine alkaloids-securinine and allosecurinine (Fig. 1). Moreover, the study elaborates propagation method including shoots proliferation, inducing roots and acclimatization. In addition, considering limited data regarding biological activity of $P$. glaucus in the presented research, the extract from in vitro shoot culture of P. glaucus, as well as isolated securinine, were used to evaluate antimicrobial activity against 12 strains of human pathogenic bacteria and one fungal strain using broth microdilution method.
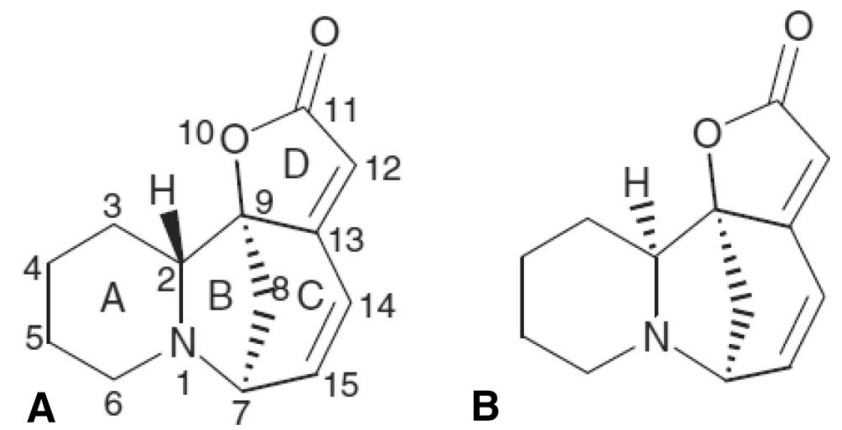

Fig. 1 Structure of securinine (a) and allosecurinine (b)

\section{Materials and methods}

\section{Culture media and growth conditions}

Thermolabile plant growth regulators [PGRs; indole-3-acetic acid (IAA), and 2-isopentenyladenine (2iP)] were added postautoclaving via sterile filtration ( $0.2 \mu \mathrm{m}$ filters, FP 3070, 2 CA-S, Schleicher and Schuell, Keene, NH, USA). The other aspects of preparation of culture media and growth conditions were described previously (Stefanowicz-Hajduk et al. 2016).

\section{Plant material and explant preparation}

The origin of the plant material and explants preparation has been described in earlier work (Sparzak et al. 2015; Stefanowicz-Hajduk et al. 2016).

\section{Influence of PGRs on shoot growth and accumulation of secondary metabolites}

The explants were placed onto MS medium (Murashige and Skoog 1962) enriched with plant growth regulators-single cytokinins -6-benzylaminopurine (BAP), kinetin (Kin), 2iP $(0.5,1.0,2.0,3.0 \mathrm{mg} / \mathrm{L})$ and 1-phenyl-3-(1,2,3-thiadiazol-5-yl) urea, thidiazuron (TDZ) $(0.05,0.1,0.2,0.5 \mathrm{mg} / \mathrm{L})$, and single auxins-indole-3-butyric acid (IBA) and IAA $(0.5,1.0$, $2.0,3.0 \mathrm{mg} / \mathrm{L})$ or a mixture of $\operatorname{BAP}$ and $\operatorname{IBA}(0.5,1.0,2.0$, $3.0 \mathrm{mg} / \mathrm{L}$ of each). The shoots length-shoots number, roots development (number and length), and the content of securinine and allosecurinine were measured after 35 days of growing. In all experiments, plant material obtained on the medium without PGRs $\left(\mathrm{MS}_{0}\right)$ was used as control.

\section{Shoots proliferation, rooting, and acclimatization of plantlets}

For maximum shoot proliferation, the shoots were inoculated on MS medium supplemented with BAP $1.0 \mathrm{mg} / \mathrm{L}$ 
IBA $0.5 \mathrm{mg} / \mathrm{L}$. After 5 weeks, single shoots were transferred onto MS medium supplemented with IBA $1.0 \mathrm{mg} / \mathrm{L}$ for root induction. Plantlets with well-developed roots were removed from the rooting medium after 5 weeks. The roots of the plantlets were washed gently with tap water to remove traces of agar and nutrients. The plantlets transferred to pots containing sterile soil or a mixture of sterile soil and perlite (2:1) and covered with plastic bags which were successively removed after 14 days. Plantlets were kept in temperature $19{ }^{\circ} \mathrm{C} \pm 2{ }^{\circ} \mathrm{C}$. After 4 weeks of hardening and acclimatization of plants, the survival frequency was recorded. After 6 months, the presence of securinega-type alkaloids in the regenerated plant material was studied.

\section{Statistical analysis}

The experiments were conducted in two series with at least 50 replicates and the results are presented as mean value $\pm \mathrm{SD}$. The differences in biomass growth and securinega-type alkaloids concentrations observed between results obtained using different PGRs were tested for statistical significance $(p<0.05)$ using the analysis of variance, followed by Tukey's range test (Statistica 10.0 software, StatSoft, Tulusa, US-OK).

\section{Preparation of extracts}

\section{Extraction of alkaloid fraction}

The extraction of securinega-type alkaloids was performed according to previously established method (Sparzak et al. 2015).

\section{Dry extract preparation for antimicrobial studies}

Preparation of dry extract was performed according to previously established method (Stefanowicz-Hajduk et al. 2016).

\section{Evaluation of securinega-type alkaloid content}

The evaluation of securinega-type alkaloids was performed according to previously established HPLC-UV (high-performance liquid chromatography) method (Sparzak et al. 2015). The content of alkaloids was calculated based on securinine. Securinine standard was purchased from Sigma-Aldrich (purity $\geq 98 \%$, HPLC).

\section{Antimicrobial activity}

\section{Test microorganisms}

Gram-positive bacteria: Clostridium sporogenes PCM2486, $\beta$-hemolytic Streptococcus group G, Enterococcus hirae
ATCC10541, Staphylococcus aureus ATCC9027, Bacillus subtilis ATCC6633, and Staphylococcus epidermidis ATCC14990.

Gram-negative bacteria: Klebsiella pneumoniae (clinical isolate), Proteus vulgaris NCTC4635, Moraxella catarrhalis PCM2340, Pseudomonas aeruginosa ATCC9077, Escherichia coli ATCC8739, and Helicobacter pylori ATCC43504. Clinical isolates were obtained from St. Adalbert Specialist Hospital in Gdańsk (Independent Public Health Care Facility in Gdańsk, Poland).

Fungus: Candida albicans ATCC10231.

\section{Antibacterial assay}

The antibacterial assay was performed according to previously established method (Krauze-Baranowska et al. 2014). Dry extract $(40 \mathrm{mg} / \mathrm{mL})$ and securinine $(1.0 \mathrm{mg} / \mathrm{mL})$ were dissolved in methanol. The final concentrations of the extracts used to the antimicrobial activity ranged from 10 to $0.01 \mathrm{mg} / \mathrm{mL}$. Securinine was also diluted in a geometric progression (concentrations from 250 to $0.024 \mu \mathrm{g} / \mathrm{mL}$ ). Ampicilin and amphotericin B were used as a positive control and MIC values were assigned. Methanol was used as negative control and MBC values were assigned.

\section{Results}

In the study on the influence of PGRs on the shoot culture of $P$. glaucus, the following cytokinins were used BAP, K, $2 \mathrm{iP}(0.5-3.0 \mathrm{mg} / \mathrm{L})$, and TDZ $(0.05-0.5 \mathrm{mg} / \mathrm{L})$, and auxins IBA and IAA $(0.5-3.0 \mathrm{mg} / \mathrm{L})$. The shoots of $P$. glaucus maintained on the PGR-free medium for 35 day showed no proliferation (control sample, $\mathrm{C} 0$ ). The average shoot length was $2.12 \pm 0.59$. At $80 \%$ of explants, spontaneous rooting was observed with an average number roots of 2.05 and the root length $2.28 \mathrm{~cm}$ (Table 1).

In the HPLC chromatograms of the alkaloid fraction from $P$. glaucus, two dominant peaks were observed with tR 5.5 min (A1) and tR 8.0 min (A2), corresponding with allosecurinine and securinine, respectively (Fig. 2). The concentration of alkaloids in the control sample was $4.49 \mathrm{mg} / \mathrm{g}$ DW (dry weight), including $1.83 \mathrm{mg} / \mathrm{g}$ DW of allosecurinine and $2.65 \mathrm{mg} / \mathrm{g}$ DW securinine (Fig. 3).

\section{The influence of cytokinins on the shoots growth and accumulation of securinega-type alkaloids}

The highest shoot/explant rate (6.8) was obtained on the medium supplemented with BAP $1.0 \mathrm{mg} / \mathrm{L}$ (Table 1). 2iP did not promote the shoot proliferation. The cytokinins caused shoot-length reduction in comparison to the control and inhibited rhizogenesis, except Kin in concentration 0.5 
Table 1 Effects of cytokinins on the growth and proliferation of $P$. glaucus shoot culture

\begin{tabular}{lll}
\hline $\begin{array}{l}\text { Plant growth regulators } \\
(\mathrm{mg} / \mathrm{L})\end{array}$ & $\begin{array}{l}\text { Proliferation rate } \\
(\text { mean } \pm \text { SD) }\end{array}$ & $\begin{array}{l}\text { Shoots' } \\
\text { length }(\mathrm{cm}) \\
(\text { mean } \pm \text { SD })\end{array}$ \\
\hline Control $\left(\mathrm{MS}_{0}\right)$ & $1.00 \pm 0.00^{\mathrm{a}}$ & $2.12 \pm 0.59^{*}$ \\
2iP 0.5 & $1.11 \pm 0.38^{\mathrm{a}}$ & $1.46 \pm 0.48^{\mathrm{a}}$ \\
2iP 1.0 & $1.17 \pm 0.43^{\mathrm{a}}$ & $1.30 \pm 0.30^{\mathrm{a}}$ \\
2iP 2.0 & $1.17 \pm 0.55^{\mathrm{a}}$ & $1.36 \pm 0.38^{\mathrm{a}}$ \\
2iP 3.0 & $1.08 \pm 0.27^{\mathrm{a}}$ & $1.23 \pm 0.33^{\mathrm{d}}$ \\
TDZ 0.05 & $1.00 \pm 0.00^{\mathrm{a}}$ & $0.71 \pm 0.25^{\mathrm{c}}$ \\
TDZ 0.1 & $1.00 \pm 0.00^{\mathrm{a}}$ & $0.62 \pm 0.22^{\mathrm{c}}$ \\
TDZ 0.2 & $1.00 \pm 0.00^{\mathrm{a}}$ & $0.56 \pm 0.17^{\mathrm{c}}$ \\
TDZ 0.5 & - & - \\
Kin 0.5 & $3.35 \pm 1.10^{\mathrm{d}}$ & $1.43 \pm 0.48^{\mathrm{a}}$ \\
Kin 1.0 & $4.02 \pm 1.46^{\mathrm{d}}$ & $1.48 \pm 0.46^{\mathrm{a}}$ \\
Kin 2.0 & $5.08 \pm 1.77^{\mathrm{b}}$ & $1.40 \pm 0.34^{\mathrm{a}}$ \\
Kin 3.0 & $5.20 \pm 1.82^{\mathrm{b}}$ & $1.38 \pm 0.31^{\mathrm{a}}$ \\
BAP 0.5 & $5.69 \pm 2.05^{\mathrm{b}}$ & $0.97 \pm 0.22^{\mathrm{b}}$ \\
BAP 1.0 & $6.80 \pm 2.99^{\mathrm{c}}$ & $1.10 \pm 0.25^{\mathrm{b}}$ \\
BAP 2.0 & $5.44 \pm 2.22^{\mathrm{b}}$ & $0.91 \pm 0.25^{\mathrm{bc}}$ \\
BAP 3.0 & $4.03 \pm 2.03^{\mathrm{d}}$ & $0.80 \pm 0.23^{\mathrm{c}}$ \\
\hline
\end{tabular}

Different letters indicate significant differences between means $(p<0.05)$

$n \geq 50 \pm \mathrm{SD}$

*A single value that does not belong to any of the groups

and $1.0 \mathrm{mg} / \mathrm{L}$ which caused root induction at $20-25 \%$ of explants (Table 1). TDZ inhibited the shoots growth in the whole range of studied concentrations (Table 1).

The influence of particular cytokinins on the level of securinega-type alkaloids was observed. BAP in all concentrations caused statistically significant increase of alkaloids concentration comparing to the control. The highest content of these metabolites $(5.82 \mathrm{mg} / \mathrm{g} \mathrm{DW})$ was achieved on MS medium supplemented with $0.5 \mathrm{mg} / \mathrm{L}$ BAP. Doserelated effect was not observed. The other cytokinins significantly decreased the total alkaloid content comparing to the control (Fig. 3). The influence of cytokinin type on the level of particular compounds in alkaloid complex was also observed. The content of securinine in biomasses obtained on the media supplemented with Kin and BAP was $2.5-3.5 \mathrm{mg} / \mathrm{g}$ DW but with TDZ twofold decrease of this alkaloid which was observed $(\sim 1.5 \mathrm{mg} / \mathrm{g}$ DW $)$ (Fig. 3). Among tested cytokinins, only an addition of BAP to the medium increased the concentration of allosecurinine (2.16-2.35 mg/g DW) comparing to the control $(1.83 \mathrm{mg} / \mathrm{g} \mathrm{DW})$; however, the difference was not statistically significant. The other cytokinins showed negative influence on allosecurinine accumulation with ca. 4.3- to 8.3-fold decrease comparing to the control (Fig. 3).

\section{The influence of auxins on the shoots' growth, rooting, and accumulation of securinega-type alkaloids}

The presence of IBA stimulated the shoot elongation, while IAA caused the shoot-length reduction comparing to the control (Table 2). Also, an addition of IBA to the medium had positive influence on the length of the root system and number of roots/explant. The efficiency of the rooting process was from 75.0 to $93.5 \%$, depending on IBA concentration (Table 2). Occasionally (14-28\% of explants), the shoots' proliferation was observed on the media with IAA.

The auxins in all concentrations showed no significant influence on the sum of alkaloids in tissues comparing to the control $(4.49 \mathrm{mg} / \mathrm{g} \mathrm{DW})$, which was in a range from 4.11 to $4.84 \mathrm{mg} / \mathrm{g} \mathrm{DW}$ for IBA and from 4.03 to $4.61 \mathrm{mg} / \mathrm{g} \mathrm{DW}$ for IAA (Fig. 4). However, both auxins caused statistically significant reduction of allosecurinine concentration. The content of securinine (3.60-4.24 mg/g DW) was even 11 times higher than allosecurinine (from 0.34 to $0.76 \mathrm{mg} / \mathrm{g}$ DW) (Fig. 4). IAA showed statistically significant stronger inhibiting effect on allosecurinine concentration comparing to IBA.

\section{The influence of concurrent supplementation of BAP and IBA on shoot proliferation and accumulation of securinega-type alkaloids}

Concurrent supplementation of the harvesting medium with BAP and IBA at concentration from 0.5 to $1.0 \mathrm{mg} / \mathrm{L}$ significantly increased shoot proliferation, comparing to the control and to the media-containing single cytokinins or auxins. As the maximum result, 11.5 shoot/explant was obtained on MS medium supplemented with BAP $1.0 \mathrm{mg} / \mathrm{L}$ and IBA $0.5 \mathrm{mg} / \mathrm{L}$ (Table 3 ). At the same time, the summary alkaloid content obtained using this medium was lower $(3.56 \mathrm{mg} / \mathrm{g}$ DW) comparing to the biomasses obtained on the medium supplemented only with BAP or IBA and to the control (Fig. 5). However, comparing to the sole supplementation with IBA, the content of securinine was reduced and the stimulation of allosecurinine accumulation was observed.

\section{Micropropagation}

For shoot proliferation, MS medium supplemented with BAP $1.0 \mathrm{mg} / \mathrm{L}$ and IBA $0.5 \mathrm{mg} / \mathrm{L}$ was used (11.5 shoot/ explants), and as the rooting medium, MS supplemented with IBA $1.0 \mathrm{mg} / \mathrm{L}$. The rooted plantlets were acclimatized in pots covered with transparent plastic bags, which were removed successively within 14 days as an adaptation stage 


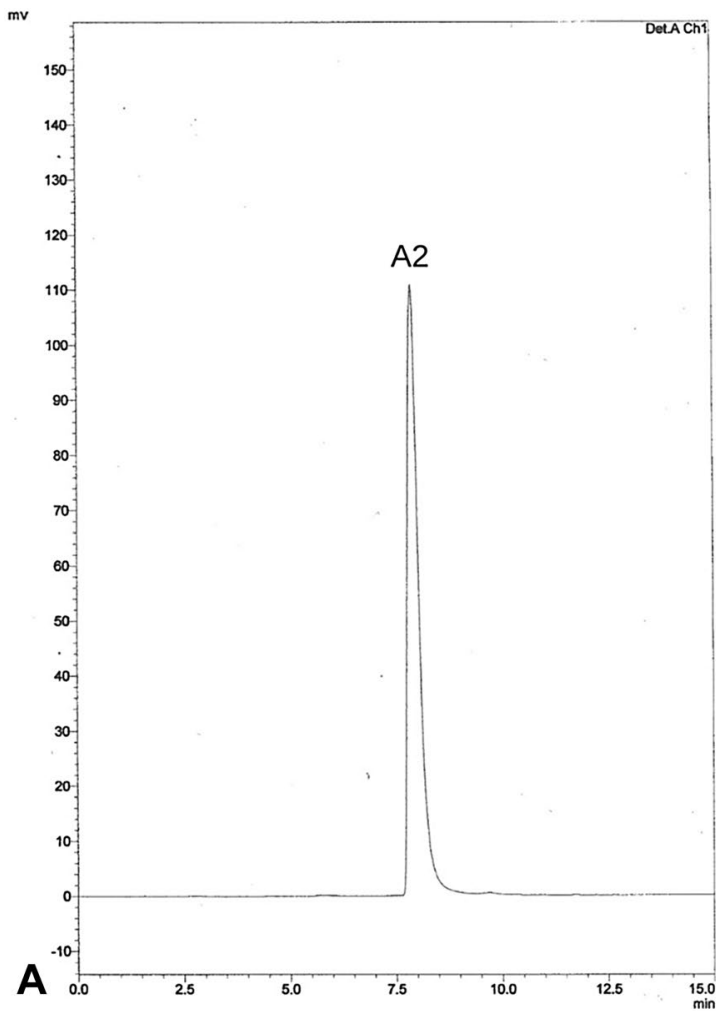

Fig. 2 HPLC-UV chromatograms of: a securinine standard and $\mathbf{b}$ alkaloid fraction from shoot culture of $P$. glaucus harvested on solid MS medium with IBA $0.5 \mathrm{mg} / \mathrm{L}$ and BAP $0.5 \mathrm{mg} / \mathrm{L}$, A1-allosecurinine, A2-securinine. Monolithic column HPLC Chromolith

between the humidity of the in vitro environment and the natural environment. $70 \%$ of explants survived after 1 month of harvesting in ex vitro conditions.

\section{Antimicrobial activity}

The results have shown varied sensitivity of the tested bacteria to $P$. glaucus extract with the $\mathrm{MBC}$ values ranging from 0.01 to $5 \mathrm{mg} / \mathrm{mL}$ (Table 4 ). The most sensitive bacterial strain was $M$. catharalis with MBC $0.01 \mathrm{mg} / \mathrm{mL}$. One bacterial strain, E. hirae, showed to be resistant to P. glaucus extract (Table 4).

Securinine proved to be active only against some of the tested bacteria in concentrations ranging from 0.063 to $0.250 \mathrm{mg} / \mathrm{mL}$. The compound did not exhibit any antimicrobial activity against E. hirae, M. catarrhalis, B. subtilis, and $C$. sporogenes. The most sensitive strains were $S$. epidermidis, $P$. aeruginosa, $H$. pylori, and C. albicans, with MBC $0.063 \mathrm{mg} / \mathrm{mL}$ (Table 4).

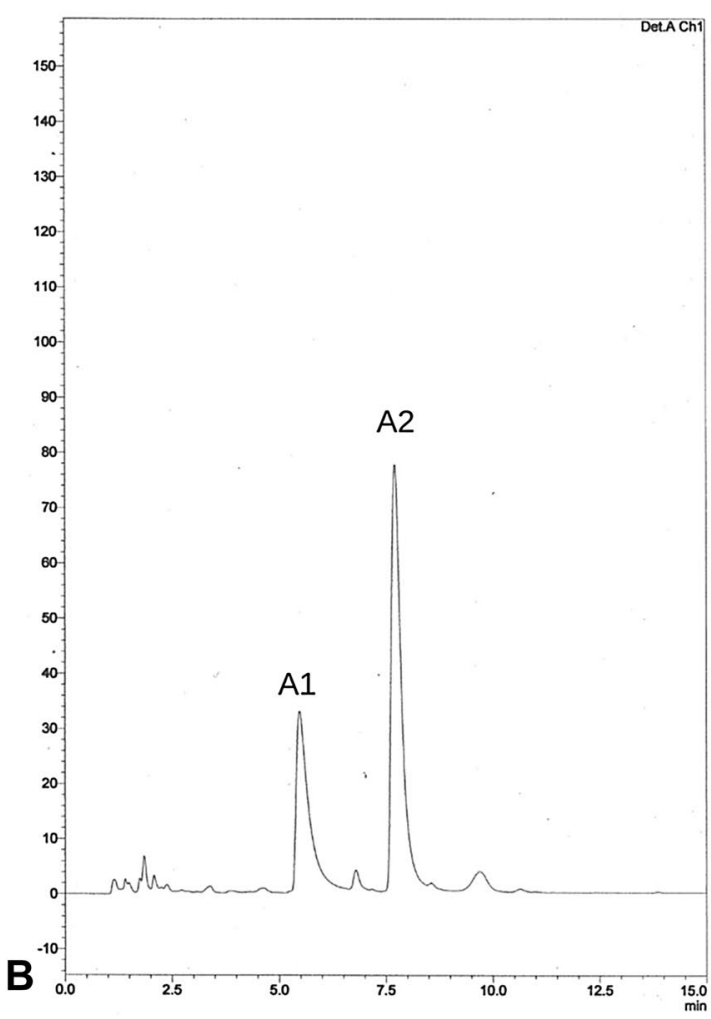

Performance RP-18E 100-4.6, $T=25{ }^{\circ} \mathrm{C}, 0 \mathrm{~min}-20 \% \mathrm{~B}, 20 \mathrm{~min}-$ $50 \% \mathrm{~B}, \mathrm{~A}-\mathrm{H} 20, \mathrm{~B}-\mathrm{CH}_{3} \mathrm{CN}$, flow rate: $1 \mathrm{~mL} / \mathrm{min}$, detection: UV $\lambda=254 \mathrm{~nm}$

\section{Discussion}

One of the most influential components of plant in vitro culture media which are crucial factors in cell and organ growth, proliferation, and metabolite accumulation are PGRs. The biosynthesis of alkaloids is strongly affected by both the type and concentration of PGRs and can be considered as a tool to improve the biosynthesis of alkaloids (Verpoorte et al. 1991). Shoots of P. glaucus were inoculated on MS medium-containing various concentrations and combinations of PGRs (40 modification in total) to investigate their influence on accumulation of securinega-type alkaloids and to select optimal conditions for shoot growth and proliferation. In the first step, the influence of single cytokinins or auxins was investigated; afterwards, the influence of supplementation with auxin and cytokinin mixture was studied.

Cytokinins used solely exhibited variable effects on $P$. glaucus shoots growth, ranging from inhibitory (TDZ), through neutral (2iP) to stimulatory (Kin, BAP) (Table 1). Despite the content of TDZ in harvesting media was significantly lower $(0.05-0.5 \mathrm{mg} / \mathrm{L})$ comparing to other cytokinins $(0.5-3.0 \mathrm{mg} / \mathrm{L})$, it inhibited the shoots growth in the whole 


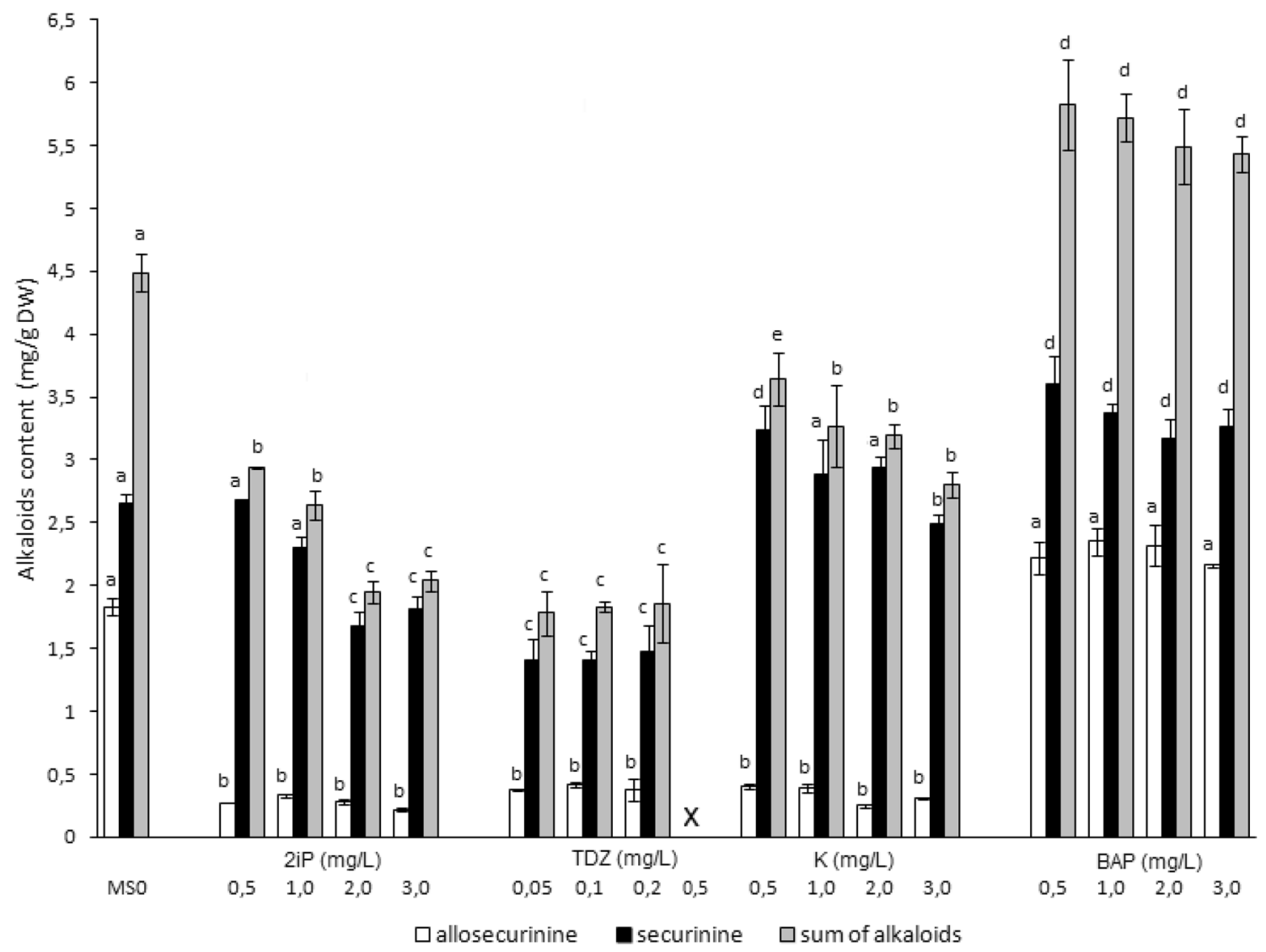

Fig. 3 Effects of cytokinins on the accumulation of indolizidine alkaloids in P. glaucus shoot culture. Different letters indicate significant differences between means $(p<0.05) . n \geq 3 \pm \mathrm{SD}$

Table 2 Effects of auxins on the growth, proliferation, and rooting of $P$. glaucus shoot culture

\begin{tabular}{llllll}
\hline $\begin{array}{l}\text { Plant growth } \\
\text { regulators }(\mathrm{mg} / \mathrm{L})\end{array}$ & $\begin{array}{l}\text { Proliferation rate } \\
(\text { mean } \pm \mathrm{SD})\end{array}$ & $\begin{array}{l}\text { Shoot length } \\
(\mathrm{cm})(\text { mean } \pm \mathrm{SD})\end{array}$ & $\begin{array}{l}\text { Root length }(\mathrm{cm}) \\
(\text { mean } \pm S D)\end{array}$ & $\begin{array}{l}\text { Root numbers } \\
(\text { mean } \pm S D)\end{array}$ & $\begin{array}{l}\text { Percent of } \\
\text { rooting }(\%)\end{array}$ \\
\hline Control $\left(\mathrm{MS}_{0}\right)$ & $1.00 \pm 0.00^{\mathrm{a}}$ & $2.12 \pm 0.59^{*}$ & $2.28 \pm 1.48^{\mathrm{a}}$ & $2.05 \pm 1.46^{\mathrm{a}}$ & 82.00 \\
IBA 0.5 & $1.00 \pm 0.00^{\mathrm{a}}$ & $2.52 \pm 0.92^{\mathrm{d}}$ & $2.50 \pm 1.69^{\mathrm{ab}}$ & $2.13 \pm 1.72^{\mathrm{ab}}$ & 75.00 \\
IBA 1 0 & $1.00 \pm 0.00^{\mathrm{a}}$ & $2.46 \pm 0.83^{\mathrm{d}}$ & $3.31 \pm 1.76^{\mathrm{c}}$ & $2.58 \pm 1.62^{\mathrm{bc}}$ & 87.50 \\
IBA 2.0 & $1.00 \pm 0.00^{\mathrm{a}}$ & $2.62 \pm 0.85^{\mathrm{d}}$ & $3.12 \pm 1.23^{\mathrm{c}}$ & $3.09 \pm 1.43^{\mathrm{d}}$ & 93.47 \\
IBA 3.0 & $1.00 \pm 0.00^{\mathrm{a}}$ & $2.94 \pm 1.05^{*}$ & $2.89 \pm 1.89^{\mathrm{bc}}$ & $2.22 \pm 1.69^{\mathrm{abc}}$ & 82.35 \\
IAA 0.5 & $1.49 \pm 0.93^{\mathrm{a}}$ & $1.87 \pm 0.89^{\mathrm{e}}$ & $2.35 \pm 1.71^{\mathrm{ab}}$ & $2.91 \pm 2.32^{\mathrm{cd}}$ & 84.21 \\
IAA 1.0 & $1.20 \pm 0.45^{\mathrm{a}}$ & $1.49 \pm 0.78^{\mathrm{a}}$ & $1.71 \pm 0.67^{\mathrm{d}}$ & $1.74 \pm 1.35^{\mathrm{abc}}$ & 80.00 \\
IAA 2.0 & $1.33 \pm 0.66^{\mathrm{a}}$ & $1.65 \pm 0.82^{\mathrm{ae}}$ & $2.20 \pm 1.73^{\mathrm{ab}}$ & $1.93 \pm 1.75^{\mathrm{abc}}$ & 77.57 \\
IAA 3.0 & $1.18 \pm 0.47^{\mathrm{a}}$ & $1.59 \pm 0.99^{\mathrm{a}}$ & $2.05 \pm 1.91^{\mathrm{ad}}$ & $1.35 \pm 1.43^{\mathrm{e}}$ & 63.16 \\
\hline
\end{tabular}

Different letters indicate significant differences between means $(p<0.05)$

$n \geq 50 \pm \mathrm{SD}$

*A single value that does not belong to any of the groups range of studied concentrations (Table 1). It confirms the results obtained by Raj et al. (2015) in the studies on Securinega suffruticosa callus culture which showed that phenylurea derivatives (TDZ, CPPU) inhibited the culture growth. Unlike Kin, BAP, and 2iP which are adenine derivatives,
TDZ is urea derivative and according to literature data while using high concentrations of this cytokinin morphological changes and growth inhibition might be observed (Murthy et al. 1998). Some studies reveal problems with conversion of the shoots induced by TDZ into complete plantlets. Also 


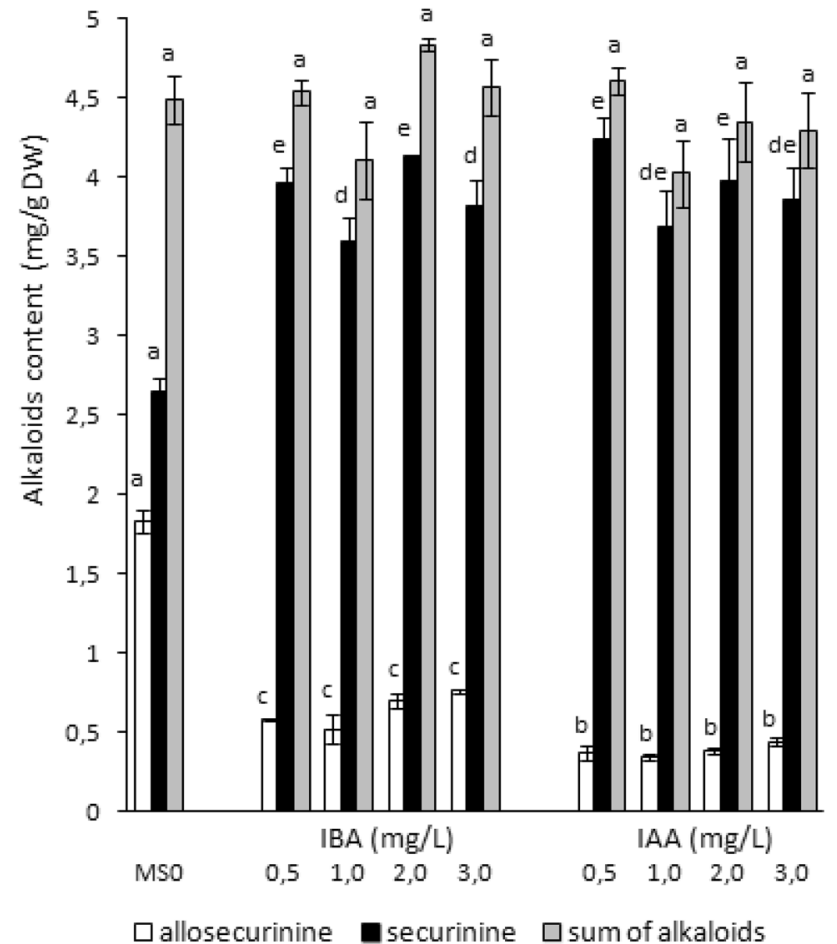

Fig. 4 Effects of auxins on the accumulation of indolizidine alkaloids in P. glaucus shoot culture. Different letters indicate significant differences between means $(p<0.05), n \geq 3 \pm \mathrm{SD}$

Table 3 Effects of mixture of BAP and IBA on the growth and proliferation of $P$. glaucus shoot culture

\begin{tabular}{|c|c|c|c|}
\hline \multicolumn{2}{|c|}{$\begin{array}{l}\text { Plant growth regulators } \\
(\mathrm{mg} / \mathrm{L})\end{array}$} & \multirow[t]{2}{*}{$\begin{array}{l}\text { Proliferation rate } \\
(\text { mean } \pm S D)\end{array}$} & \multirow{2}{*}{$\begin{array}{l}\text { Shoot } \\
\text { length }(\mathrm{cm}) \\
(\text { mean } \pm S D)\end{array}$} \\
\hline BAP & IBA & & \\
\hline Control $\left(\mathrm{MS}_{0}\right)$ & & $1.00 \pm 0.00^{\mathrm{a}}$ & $2.12 \pm 0.59 *$ \\
\hline 0.5 & 0.5 & $7.91 \pm 2.68^{c}$ & $1.36 \pm 0.33^{\mathrm{a}}$ \\
\hline 1.0 & 0.5 & $11.50 \pm 5.10^{\mathrm{f}}$ & $1.07 \pm 0.39^{\mathrm{b}}$ \\
\hline 2.0 & 0.5 & $5.62 \pm 2.83^{\mathrm{b}}$ & $0.85 \pm 0.26^{\mathrm{c}}$ \\
\hline 3.0 & 0.5 & $4.24 \pm 2.92^{\mathrm{d}}$ & $0.73 \pm 0.35^{\mathrm{c}}$ \\
\hline 0.5 & 1.0 & $9.85 \pm 3.21^{\mathrm{e}}$ & $1.32 \pm 0.33^{\mathrm{a}}$ \\
\hline 1.0 & 1.0 & $9.96 \pm 4.14^{\mathrm{e}}$ & $1.04 \pm 0.34^{\mathrm{b}}$ \\
\hline 2.0 & 1.0 & $4.96 \pm 3.03^{\mathrm{bd}}$ & $0.79 \pm 0.27^{\mathrm{c}}$ \\
\hline 3.0 & 1.0 & $4.16 \pm 2.33^{\mathrm{d}}$ & $0.79 \pm 0.42^{\mathrm{c}}$ \\
\hline 0.5 & 2.0 & $7.51 \pm 3.22^{c}$ & $1.31 \pm 0.28^{\mathrm{a}}$ \\
\hline 1.0 & 2.0 & $10.63 \pm 5.28^{\mathrm{ef}}$ & $1.05 \pm 0.24^{\mathrm{b}}$ \\
\hline 2.0 & 2.0 & $5.59 \pm 2.99^{b}$ & $0.86 \pm 0.27^{\mathrm{c}}$ \\
\hline 3.0 & 2.0 & $4.73 \pm 3.28^{\mathrm{bd}}$ & $0.68 \pm 0.32^{\mathrm{c}}$ \\
\hline 0.5 & 3.0 & $6.54 \pm 2.59^{\mathrm{bc}}$ & $1.45 \pm 0.41^{\mathrm{a}}$ \\
\hline 1.0 & 3.0 & $7.91 \pm 4.64^{\mathrm{c}}$ & $0.94 \pm 0.21^{\mathrm{c}}$ \\
\hline 2.0 & 3.0 & $5.76 \pm 2.55^{\mathrm{b}}$ & $0.84 \pm 0.27^{\mathrm{c}}$ \\
\hline 3.0 & 3.0 & $3.20 \pm 1.97^{\mathrm{d}}$ & $0.78 \pm 0.31^{\mathrm{c}}$ \\
\hline
\end{tabular}

Different letters indicate significant differences between means $(p<0.05)$

$n \geq 50 \pm \mathrm{SD}$

*A single value that does not belong to any of the groups the addition of TDZ to the harvesting medium may result in poor elongation of shoots and inadequate rooting (Murthy et al. 1998).

Although $2 \mathrm{iP}$ belongs to adenine derivatives, as it was stated, it did not promote the shoot proliferation (Sujatha and Reddy 1998). In addition, it was observed that, on the medium supplemented with $2 \mathrm{iP}$, the lowest leaves which had contact with harvesting medium became brown. The maximum proliferation was achieved on the medium with BAP $1.0 \mathrm{mg} / \mathrm{L}$ (6.8 shoot/explants) and this cytokinin was selected for further experiments.

Among auxins, the presence of IBA in the medium stimulated the shoot elongation comparing to the control (Table 2) and possessed positive influence on the development of roots. Shoot proliferation which was observed on the media with IAA (14-28\% of explants) is unwanted during microshoot rooting and elongation during micropropagation process. It is worth to notice that the presence of auxins in harvesting medium, at concentration higher than $1.0 \mathrm{mg} / \mathrm{L}$, caused the roots obtained to be delicate, fragile, and breakable.

In the next part of the study, the PGRs which provided the best results (BAP and IBA) were applied jointly to verify their synergistic effect and it was shown that concurrent supplementation significantly increased shoot proliferation, compared to the control and to the media-containing single cytokinins or auxins. As the maximum result, 11.5 shoot/ explant was obtained (MS BAP $1.0 \mathrm{mg} / \mathrm{L}$ and IBA $0.5 \mathrm{mg} / \mathrm{L}$ ) (Table 3).

Considering the shoots of $P$. glaucus as the source of indolizidine alkaloids which possess interesting biological activity and the fact that availability of the species in natural habitat is limited to India, Buthan, and Nepal, the above results were used to establish micropropagation protocol using MS medium supplemented with BAP $1.0 \mathrm{mg} / \mathrm{L}$ and IBA $0.5 \mathrm{mg} / \mathrm{L}$ for shoot proliferation, and as the rooting MS medium supplemented with IBA $1.0 \mathrm{mg} / \mathrm{L}$ (Fig. 6). At the acclimatization stage, it was seen that plantlets were susceptible to excessive soil irrigation, which resulted in plantlet infection and leaf loss. The process was particularly increased, while, using the mixture of soil and perlite, therefore, in the routine acclimatization stage, only the soil was used without the addition of perlite. Phytochemical investigation of the regenerated plant material showed that the total alkaloid content was significantly higher $(14.11 \mathrm{mg} / \mathrm{g}$ DW) (Sparzak et al. 2015), compared to the shoot culture harvested on medium for shoot proliferation $(3.56 \mathrm{mg} / \mathrm{g} \mathrm{DW})$ and rooting medium $(4.11 \mathrm{mg} / \mathrm{g} \mathrm{DW})$.

Thus far, the conditions for micropropagation have been developed for several Phyllanthus species, e.g., P. amarus, $P$. fraternus, $P$. niruri, $P$. emblica, $P$. stipulatus, $P$. urinaria, and $P$. caroliniensis (Catapan et al. 2000, 2001, 2002; Ghanti et al. 2004; Nayak et al. 2010; Ong and Chan 2006; 


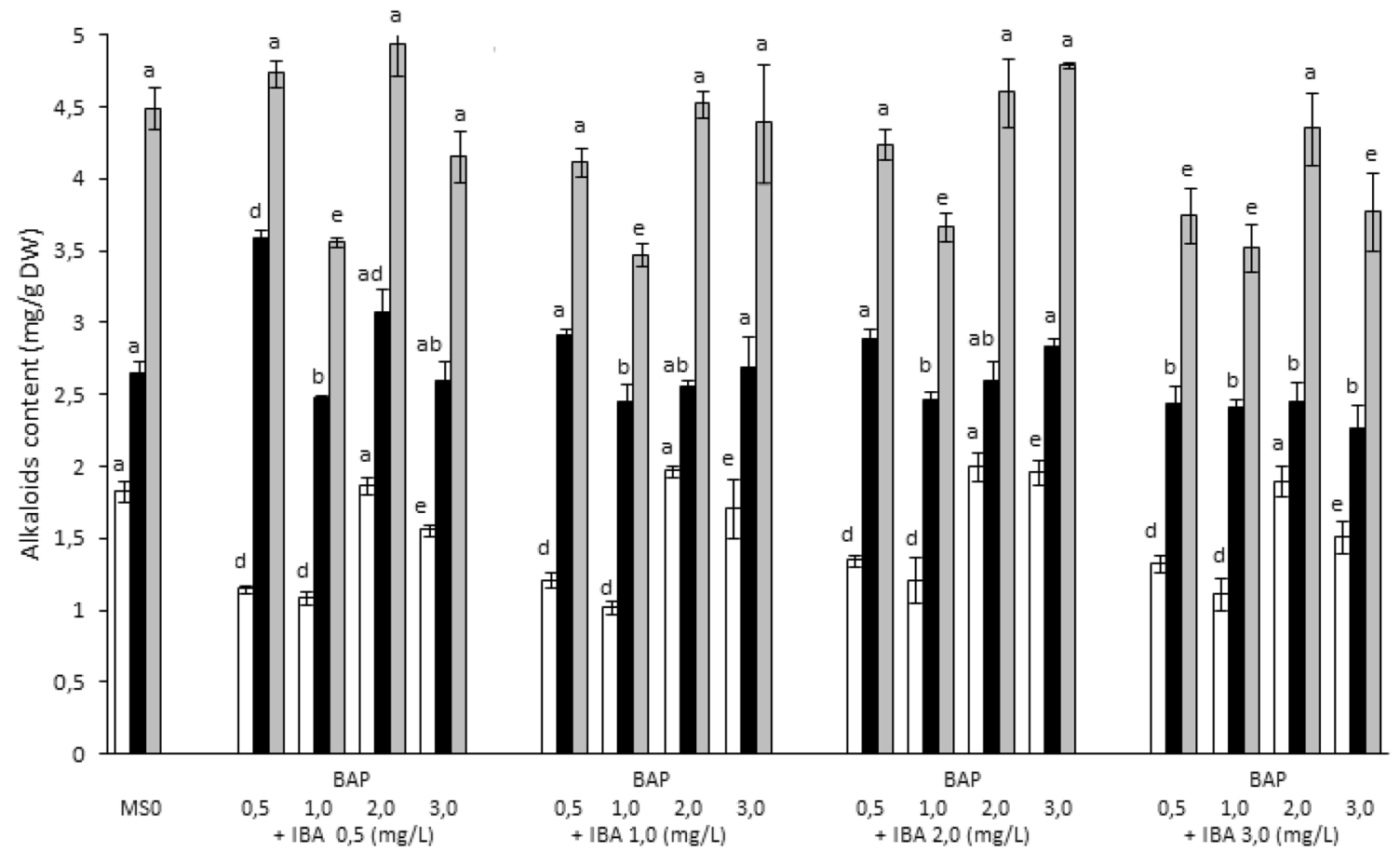

$\square$ allosecurinine securinine $\square$ sumotalkaloids

Fig. 5 Effects of mixture of BAP and IBA on the accumulation of indolizidine alkaloids in P. glaucus shoot culture. Different letters indicate significant differences between means $(p<0.05), n \geq 3 \pm \mathrm{SD}$

Table 4 Antimicrobial activity of $P$. glaucus extract $(\mathrm{mg} / \mathrm{mL})$, securinine $(\mathrm{mg} / \mathrm{mL})$, ampicillin/amphotericin B (positive control, $\mathrm{mg} / \mathrm{mL})$, and methanol (negative control, \%)

\begin{tabular}{|c|c|c|c|c|c|c|c|}
\hline \multirow[t]{2}{*}{ Bacterial/fungal strain } & \multicolumn{2}{|c|}{$\begin{array}{l}\text { P. glaucus shoot } \\
\text { culture }\end{array}$} & \multicolumn{2}{|c|}{ Securinine } & \multirow{2}{*}{$\begin{array}{l}\text { Ampicilin/ } \\
\text { amphotericin } \mathrm{B}^{\mathrm{a}} \\
\text { MIC }\end{array}$} & \multirow{2}{*}{$\begin{array}{l}\text { Methanol (\%) } \\
\text { MBC }\end{array}$} & \multirow{2}{*}{$\begin{array}{l}\text { Methanol concentration in } \\
\text { the extracts with antibacterial } \\
\text { activity } \\
\%\end{array}$} \\
\hline & MIC & $\mathrm{MBC}$ & MIC & MBC & & & \\
\hline Streptococcus G & 0.625 & 0.625 & 0.031 & 0.125 & 0.0002 & 6.25 & 0.78 \\
\hline Enterococcus hirae & - & - & - & - & 0.0025 & $>25$ & - \\
\hline Moraxella catarrhalis & 0.01 & 0.01 & - & - & 0.0025 & 0.8 & 0.025 \\
\hline Staphylococcus epidermidis & 2.5 & 5.0 & 0.063 & 0.063 & 0.0003 & 6.25 & 6.25 \\
\hline Staphylococcus aureus & 1.25 & 5.0 & 0.125 & 0.250 & 0.0003 & 25.0 & 3.12 \\
\hline $\begin{array}{l}\text { Escherichia } \\
\text { coli }\end{array}$ & 2.5 & 5.0 & 0.125 & 0.125 & 0.0078 & 25.0 & 6.25 \\
\hline Klebsiella pneumoniae & 5.0 & 5.0 & 0.125 & 0.125 & 0.0625 & 25.0 & 12.5 \\
\hline $\begin{array}{l}\text { Proteus } \\
\text { vulgaris }\end{array}$ & 1.25 & 2.5 & 0.125 & 0.125 & 0.0039 & 25.0 & 3.12 \\
\hline Pseudomonas aeruginosa & 2.5 & 2.5 & 0.031 & 0.063 & 1.5630 & 12.5 & 6.25 \\
\hline $\begin{array}{l}\text { Bacillus } \\
\text { subtilis }\end{array}$ & 5.0 & 5.0 & - & - & 0.00005 & $>25$ & 12.5 \\
\hline Clostridium sporogenes & 0.8 & 0.8 & - & - & 0.0010 & 12.5 & 0.2 \\
\hline Helicobacter pylori & a & 5.0 & $\mathrm{a}$ & 0.063 & 0.0033 & $>25$ & 12.5 \\
\hline $\begin{array}{l}\text { Candida } \\
\text { albicans }\end{array}$ & 2.5 & 2.5 & 0.063 & 0.063 & $0.0005^{\mathrm{a}}$ & 25.0 & 6.25 \\
\hline
\end{tabular}

- No antimicrobial activity in tested concentration

${ }^{\mathrm{a}} \mathrm{MIC}$ value was not analyzed 

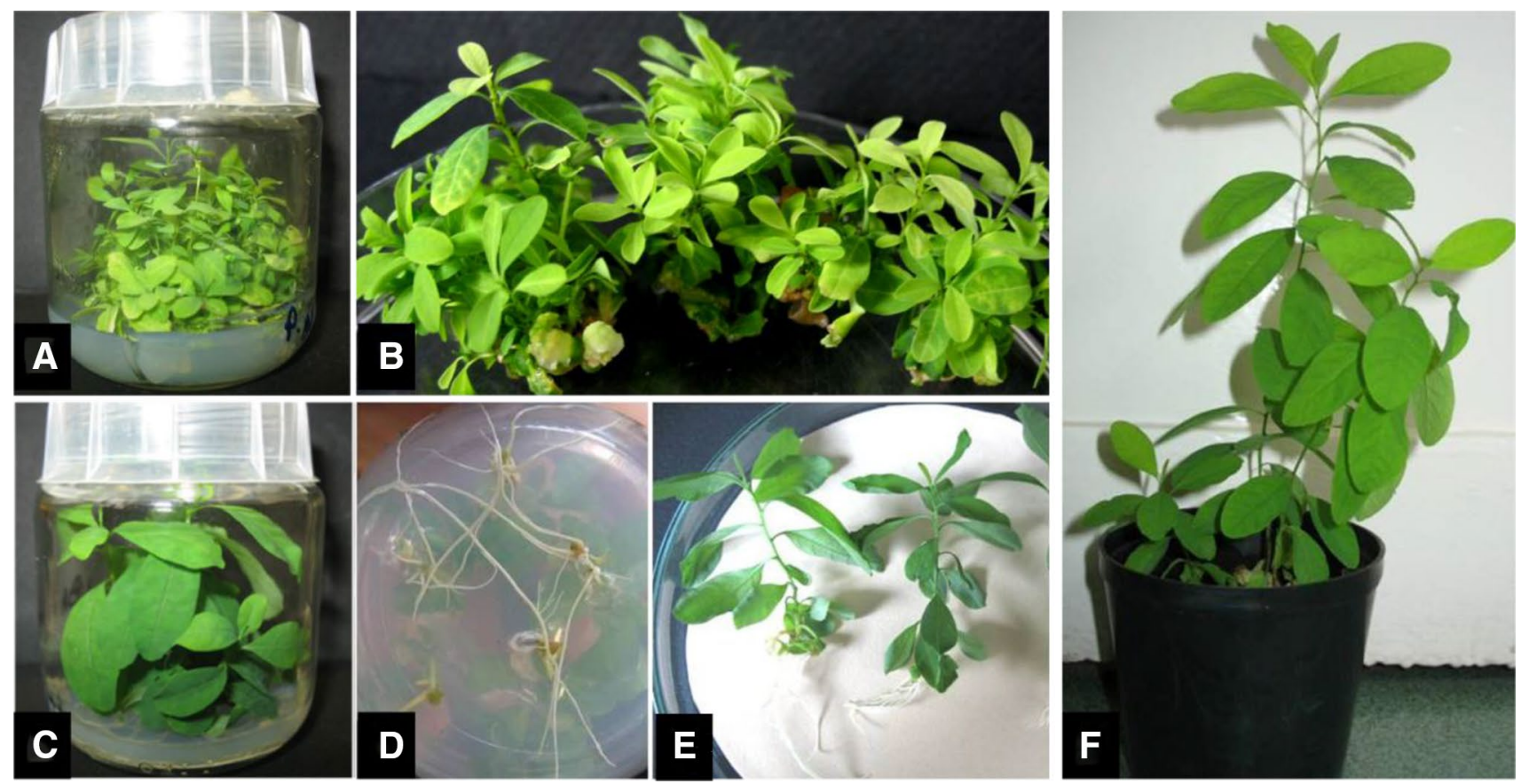

Fig. 6 Micropropagation cycle of $P$. glaucus. a, b Multiple shoot regeneration on MS medium supplemented with BAP $1.0 \mathrm{mg} / \mathrm{L}$ and IBA $0.5 \mathrm{mg} / \mathrm{L}$. c, d Shoots elongation and roots development on MS

Rajasubramaniam and Saradhi 1997). Cytokinins-BAP and Kin-are most often used for multiple shoot formation in the micropropagation of Phyllanthus species. Using the mentioned phytohormones, depending on the species, from several to over a dozen shoots were obtained (Catapan et al. 2000, 2001, 2002; Ghanti et al. 2004; Nayak et al. 2010; Ong and Chan 2006; Rajasubramaniam and Saradhi 1997). However, in the presence of $2 \mathrm{iP}$, more than 20 shoots/explant were obtained for $P$. urinaria (Catapan et al. 2002). IBA is very often used in the rooting process during micropropagation of Phyllanthus species (Ghanti et al. 2004; Nayak et al. 2010; Rajasubramaniam and Saradhi 1997) and efficiency of this process is from 70 to $100 \%$ which is confirmed by the results of performed experiment concerning $P$. glaucus (75.0-93.5\%, depending on IBA concentration) (Table 2).

The highest content of securinega-type alkaloids $(5.82 \mathrm{mg} / \mathrm{g} \mathrm{DW})$ was obtained using BAP at a concentration $0.5 \mathrm{mg} / \mathrm{L}$. It was also observed that, among the cytokinins used, only BAP caused an increase in the concentration of allosecurinine in the obtained biomass in comparison to the control (Table 1). The auxins at all concentrations showed no significant influence on the sum of alkaloids in tissues compared to the control. However, they caused statistically significant reduction of allosecurinine concentration, making the $P$. glaucus biomasses an almost selective source of securinine. Compared to the sole supplementation with IBA, in the biomass obtained on the medium supplemented with medium supplemented with IBA $1.0 \mathrm{mg} / \mathrm{L}$. e In vitro rooted, regenerated plantlets, $f$ acclimatized plant after 2 months

both auxin and cytokinin, the content of securinine was reduced and the stimulation of allosecurinine production was observed. It was probably the result of the reversal of the IBA negative effect on allosecurinine accumulation by cytokinin.

The literature data concerning accumulation of indolizidine alkaloids and the influence of PGRs on its content in in vitro culture are limited to Securinega species (Raj et al. 2015; Yuan et al. 2007). In the study performed by Raj et al., it was showed that the addition of $0.5 \mathrm{mg} / \mathrm{L}$ Kin to the harvesting medium significantly increased allosecurinine concentration $(3.12 \mathrm{mg} / \mathrm{g} \mathrm{DW})$ in the callus culture of $S$. suffruticosa, compared to the biomass maintained on the PGR-free medium (control) (Raj et al. 2015). However, contrary to $P$. glaucus shoot culture, the concentration of allosecurinine in the control sample was over twofold higher $(1.42 \mathrm{mg} / \mathrm{g} \mathrm{DW})$ than that of securinine $(0.61 \mathrm{mg} / \mathrm{g} \mathrm{DW})$. In addition, contrary to the effect observed for $P$. glaucus simultaneous supplementation with cytokinin $(5.0 \mathrm{mg} / \mathrm{L}$ Kin) and auxin $(0.5 \mathrm{mg} / \mathrm{L}$ IAA) significantly increased allosecurinine concentration $(3.11 \mathrm{mg} / \mathrm{g} \mathrm{DW})$ comparing to the control. None of the auxin supplemented at $0.5 \mathrm{mg} / \mathrm{L}$ (including IBA) applied jointly with $5.0 \mathrm{mg} / \mathrm{L}$ Kin had statistically significant stimulatory effect on securinine accumulation (Raj et al. 2015).

The influence of PGRs on biosynthesis of indolizidine alkaloids in in vitro culture of Securinega species was also 
investigated by Yuan et al. (2007) and Ide (1991). However, because of the differences in experiments (PGR type and concentrations applied, type of culture, and investigated compounds), it is difficult to compare directly the results of the previous studies with the current work.

The content of alkaloids in the biomass of $P$. glaucus obtained on the medium with the highest proliferation rate was significantly lower $(3.56 \mathrm{mg} / \mathrm{g}$ DW) comparing to the control $(4.49 \mathrm{mg} / \mathrm{g} \mathrm{DW})$. As the result of that, to obtain the plant material for alkaloid isolation and the source of explants for further experiment concerning biological activity, in routine propagation, MS IBA $0.5 \mathrm{mg} / \mathrm{L}$, BAP $0.5 \mathrm{mg} / \mathrm{L}$ medium was used. It was a compromise between relatively high proliferation rate ( 8 shoots/explant) and total content of alkaloids (4.73 mg/g DW).

There are limited results concerning the antimicrobial activity of securinega-type alkaloids. In the study of antimicrobial activity of Phyllanthus discoideus, it was showed that alkaloid fraction inhibited growth of E. coli and E. faecium (MIC $-1.6 \mathrm{mg} / \mathrm{mL}$ ), P. aeruginosa (MIC $-0.78 \mathrm{mg}$ / $\mathrm{mL}$ ), and S. aureus and M. smegmatis (MIC $=0.2 \mathrm{mg} / \mathrm{mL}$ ). Among the compounds identified in the alkaloid fraction, the highest activity was revealed for allosecurinine and securinine. Viroallosecurinine showed an MIC of $0.48 \mu \mathrm{g} / \mathrm{mL}$ towards $P$. aeruginosa and $S$. aureus. The MIC of securinine was $0.500 \mathrm{mg} / \mathrm{mL}$ towards E. coli, S. aureus, and M. smegmatis (Mensah et al. 1990).

The biomass of $P$. glaucus and isolated securinine, as the main biologically active compound of $P$. glaucus, were evaluated in a range of antimicrobial activity which was estimated towards 12 strains of human pathogenic bacteria, both Gram-negative and Gram-positive, and 1 fungal strain using broth microdilution method. Sensitivity of bacteria to $P$. glaucus extract was estimated for the first time. Antimicrobial activity of the analyzed extract was compared to that of securinine. Both, the extract and compound, proved to be active against most of the tested bacterial strains. However, they showed differences in activity against particular microorganisms. Among the analyzed bacterial strains, the most sensitive strain turned out to be $M$. catharalis (MBC $0.01 \mathrm{mg} / \mathrm{mL}$ ) - human, commensal pathogen that causes respiratory tract infections. The concentration of methanol in bactericidal extracts was in most of them from 2 to 64 times lower than its bactericidal concentration itself against the investigated microorganisms (Table 4).

Securinine showed no antimicrobial activity against E. hirae, M. catarrhalis, B. subtilis, and C. sporogenes, which suggests that the antibacterial activity of $P$. glaucus extract against these strains is probably independent of this compound.

There are some reports concerning the activity of Phyllanthus extracts against $H$. pylori; however, the antimicrobial potential of securinine against this pathogen has not been evaluated up to the present time. The activity of water extracts of $P$. niruri and methanol and chloroform extracts of $P$. urinaria against $H$. pylori was investigated using disk agar diffusion method (Lai et al. 2008; Ranilla et al. 2012). The water extract which contained ellagic acid and hydroxycinnamic acid derivatives caused $H$. pylori inhibition in a dose-dependent manner (25-100 mg of dried sample/mL). No inhibition zone was observed for pure phenolic acids - chlorogenic, ellagic, and gallic acids (Ranilla et al. 2012). In addition, the methanol and chloroform extracts showed to be more potent than its isolates (lignans and polyphenols) (Lai et al. 2008). Our study revealed that the methanol extract from $P$. glaucus has an antibacterial effect against $H$. pylori at MBC of $5 \mathrm{mg} / \mathrm{mL}$, and the isolated securinine will probably be responsible for this activity, showing a significantly lower MBC value of $0.063 \mathrm{mg} / \mathrm{mL}$.

As a conclusion, differences in influence of PGRs on the biomass growth and the content of indolizidine alkaloids in the shoot culture of $P$. glaucus were revealed. Regarding the literature data, it can be stated that the effect of PGRs on indolizidine alkaloids accumulation in in vitro cultures strongly depends on the plant genus and culture type. In addition, taking into account the obtained results, it can be stated that the composition of PGRs in the growth medium is difficult to optimize for both the highest proliferation rate and the alkaloid accumulation. The propagation method for P. glaucus was established including shoot regeneration, shoot proliferation, rooting, and acclimatization. The results can be used for large-scale propagation of $P$. glaucus or to obtain biomass which can be an alternative source for the production of securinega-type alkaloids, securinine, and allosecurinine. In addition, these are first data concerning the antimicrobial activity of $P$. glaucus.

Author contribution statement BS-S designed and performed experiments concerning plant in vitro culture and phytochemical analysis, analyzed the data, and wrote the paper. MK-B designed and oversaw experiments, analyzed the data, and corrected and revised the manuscript. RH performed experiments concerning antimicrobial activity. All authors read and approved the final manuscript.

Funding The study was funded by National Science Centre, Poland (Grant number DEC 2012/05/N/NZ/00957).

\section{Compliance with ethical standards}

Conflict of interest The authors declare that they have no conflict of interest. 
Ethical approval This article does not contain any studies with human participants or animals performed by any of the authors.

Open Access This article is distributed under the terms of the Creative Commons Attribution 4.0 International License (http://creativeco mmons.org/licenses/by/4.0/), which permits unrestricted use, distribution, and reproduction in any medium, provided you give appropriate credit to the original author(s) and the source, provide a link to the Creative Commons license, and indicate if changes were made.

\section{References}

Babady B, Gedris TE, Herz W (1996) Niruroidine, a norsecurininetype alkaloid from Phyllanthus niruroides. Phytochemistry 41:1441-1443

Beutler JA, Brubaker AN (1987) The chemistry and pharmacology of the securinine alkaloids. Drugs Future 12:957-976

Beutler JA, Karbon EW, Brubaker AN, Malik R, Curtis DR, Enna SJ (1985) Securinine alkaloids: a new class of GABA receptor antagonist. Brain Res 330:135-140

Calixto JB, Santos ARS, Cechinel Filho V, Yunes RA (1998) A review of the plants of the genus Phyllanthus: their chemistry, pharmacology, and therapeutic potential. Med Res Rev 18:225-258

Catapan E, Otuki MF, Viana AM (2000) In vitro culture of Phyllanthus caroliniensis (Euphorbiaceae). Plant Cell Tissue Organ Cult 62:195-202

Catapan E, Otuki MF, Viana AM (2001) In vitro culture of Phyllanthus stipulatus (Euphorbiaceae). Rev Bras Bot 24:25-34

Catapan E, Luís M, Da Silva B, Netto Moreno F, Maria Viana A (2002) Micropropagation, callus and root culture of Phyllanthus urinaria (Euphorbiaceae). Plant Cell Tissue Organ Cult 70:301-309

Dong NZ, Gu ZL, Chou WH, Kwok CY (1999) Securinine induced apoptosis in human leukemia HL-60 cells. Acta Pharm Sin 20:267-270

Ghanti KS, Govindaraju B, Venugopal RB, Ramgopal Rao S, Kaviraj CP, Jabeen FTZ, Barad A, Rao S (2004) High frequency shoot regeneration from Phyllanthus amarus Schum. \& Thonn. Indian J Biotechnol 3:103-107

Gupta K, Chakrabarti A, Rana S, Ramdeo R, Roth BL, Agarwal ML, Tse W, Agarwal MK, Wald DN (2011) Securinine, a myeloid differentiation agent with therapeutic potential for AML. PLoS One 6:e21203

Houghton PJ, Woldemariam TZ, O'Shea S, Thyagarajan SP (1996) Two securinega-type alkaloids from Phyllanthus amarus. Phytochemistry 43:715-717

Ide A (1991) Securinega suffruticosa: in vitro culture and the formation of securinega alkaloids. In: Bajaj YPS (ed) Biotechnology in agriculture and forestry, vol 15: medicinal and aromatic plants III. Springer, Berlin, pp 420-431

Krauze-Baranowska M, Majdan M, Halasa R, Glod D, Kula M, Fecka I, Orzel A (2014) The antimicrobial activity of fruits from some cultivar varieties of Rubus idaeus and Rubus occidentalis. Food Funct 5:2536-2541

Lai CH, Fang SH, Rao YK, Geethangili M, Tang CH, Lin YJ, Hung CH, Wang WC, Tzeng YM (2008) Inhibition of Helicobacter pylori-induced inflammation in human gastric epithelial AGS cells by Phyllanthus urinaria extracts. J Ethnopharmacol 118:522-526

Li M, Han S, Zhang G, Wang Y, Ji Z (2014) Antiproliferative activity and apoptosis-inducing mechanism of $\mathrm{L}$-securinine on human breast cancer MCF-7 cells. Pharmazie 69:217-223

Lin X, Jun-Tian Z (2004) Neuroprotection by D-securinine against neurotoxicity induced by beta-amyloid (25-35). Neurol Res $26: 792-796$
Mensah JL, Gleye J, Moulis C, Fouraste I (1988) Alkaloids from the leaves of Phyllanthus discoideus. J Nat Prod 51:1113-1115

Mensah JL, Lagarde I, Ceschin C, Michel G, Gleye J, Fouraste I (1990) Antibacterial activity of leaves of Phyllanthus discoideus. J Ethnopharmacol 28:129-133

Murashige T, Skoog F (1962) A revised medium for rapid growth and bioassays with tobacco tissue cultures. Physiol Plant 15:473-497

Murthy BNS, Murch SJ, Saxena PK (1998) Thidiazuron: a potent regulator of in vitro plant morphogenesis. In Vitro Cell Dev Plant 34:267-275

Nayak P, Behera PR, Thirunavoukkarasu M, Chand PK (2010) High frequency plant regeneration through adventitious multiple shoot organogenesis in epicotyl explants of Indian gooseberry (Emblica officinalis Gaertn). Sci Hortic 123:473-478

Negi RS, Fakhir TM (1988) Simplexine (14-hydroxy-4-methoxy-13, 14-dihydronorsecurinine): an alkaloid from Phyllanthus simplex. Phytochemistry 27:3027-3028

Ong PL, Chan LK (2006) In vitro plant regeneration, flowering and fruiting of Phyllanthus niruri L. (Euphorbiaceae). Int J Bot 2:409-414

Raj D, Kokotkiewicz A, Drys A, Luczkiewicz M (2015) Effect of plant growth regulators on the accumulation of indolizidine alkaloids in Securinega suffruticosa callus cultures. Plant Cell Tissue Organ Cult 123:39-45

Rajasubramaniam S, Saradhi PP (1997) Rapid multiplication of Phyllanthus fratevnus: a plant with anti-hepatitis viral activity. Ind Crop Prod 6:35-40

Rana S, Gupta K, Gomez J, Matsuyama S, Chakrabarti A, Agarwal ML, Agarwal A, Agarwal MK, Wald DN (2010) Securinine induces p73-dependent apoptosis preferentially in p53-deficient colon cancer cells. FASEB J 24:2126-2134

Ranilla LG, Apostolidis E, Shetty K (2012) Antimicrobial activity of an amazon medicinal plant (Chancapiedra) (Phyllanthus niruri L.) against Helicobacter pylori and lactic acid bacteria. Phytother Res 26:791-799

Sparzak B, Dybowski F, Krauze-Baranowska M (2015) Analysis of Securinega-type alkaloids from Phyllanthus glaucus biomass. Phytochem Lett 11:353-357

Stefanowicz-Hajduk J, Sparzak-Stefanowska B, Krauze-Baranowska M, Ochocka RJ (2016) Securinine from Phyllanthus glaucus induces cell cycle arrest and apoptosis in human cervical cancer HeLa cells. PLoS One 11:e0165372

Sujatha M, Reddy TP (1998) Differential cytokinin effects on the stimulation of in vitro shoot proliferation from meristematic explants of castor (Ricinus communis L.). Plant Cell Rep 17:561-566

Verpoorte R, van der Heijden R, van Gulik WM, ten Hoopen HJG (1991) Plant biotechnology for the production of alkaloids: present status and prospects. In: Brossi A (ed) The alkaloids: chemistry and pharmacology, vol 40. Academic Press, San Diego, pp $1-187$

Xia YH, Cheng CR, Yao SY, Zhang Q, Wang Y, Ji ZN (2011) L-Securinine induced the human colon cancer SW480 cell autophagy and its molecular mechanism. Fitoterapia 82:1258-1264

Yuan W, Zhu P, Cheng K, Meng C, Ma L, Wu F, Zhu H (2007) Callus of Securinega suffruticosa, a cell line accumulates dextro Securinega alkaloids. Nat Prod Res 21:234-242

Zhang W, Li JY, Lan P, Sun PH, Wang Y, Ye WC, Chen WM (2011) Chemical synthesis and biological activities of Securinega alkaloids. J Chin Pharm Sci 20:203-217

Zhou M, Zhu H, Wang K, Wei W, Zhang Y (2012) Isolation and X-ray crystal structure of a securinega-type alkaloid from Phyllanthus niruri Linn. Nat Prod Res 26:762-764

Publisher's Note Springer Nature remains neutral with regard to jurisdictional claims in published maps and institutional affiliations. 